Journal of Materials and Environmental Sciences ISSN : 2028-2508

CODEN : JMESCN

Copyright $\odot 2017$

University of Mohammed Premier

Oujda Morocco
J. Mater. Environ. Sci., 2018, Volume 9, Issue 1, Page 100-106

https://doi.org/10.26872/jmes.2018.9.1.12

\title{
Effect of Variation in Frequencies on Dynamic Mechanical Properties of Jute Fibre Reinforced Epoxy Composites
}

\author{
M. K. Gupta \\ Department of Mechanical Engineering, Motilal Nehru National Institute of Technology Allahabad, Allahabad-211004, \\ India
}

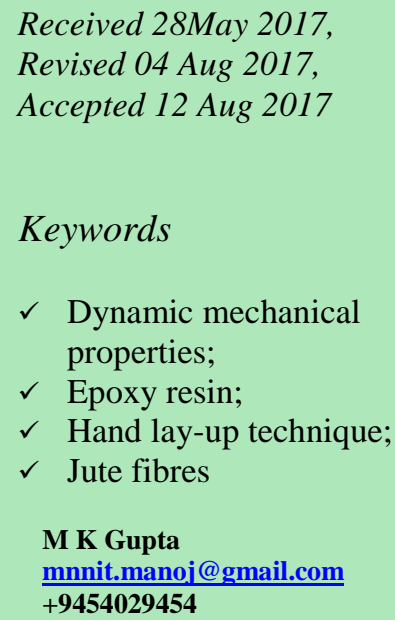

\begin{abstract}
In present work, jute fibre reinforced epoxy composites were prepared by hand lay-up technique followed by static compression using varying weight percentages $(10,20,30$ and 40) of jute fibres. The prepared jute composites were subjected to study its dynamic mechanical properties in terms of storage modulus $\left(E^{\prime}\right)$, loss modulus $\left(E^{\prime \prime}\right)$, damping ( $\operatorname{Tan} \delta$ ) and glass transition temperature $\left(T_{g}\right)$ at different frequencies i.e. 1, 2, 5 and $10 \mathrm{~Hz}$. The results indicated that thermal stability and load bearing capacity was found to improve with increase in fibres loading in the composites. In addition to this, it was also observed that variation in frequencies had a significant effect on dynamic mechanical properties of jute composites. The acceptable dynamic mechanical properties of present jute composite indicate that it can be used in making the casing of electronics instruments such mobiles, laptops etc. apart from its traditional applications such as packaging and constructions.
\end{abstract}

\section{Introduction}

For environmental and ecological concern, natural fibres reinforced polymer composites (NFRPCs) may be better alternative of synthetic fibre reinforced polymer composite due to compensation of low cost, low density, biodegradability, recyclability, availability in abundance and acceptable mechanical properties [1-6]. Nowadays, NFRPCs have been widely used materials in many applications such as automobile, packaging and construction industries [7-13]. In addition, applications of NFRPCs are rapidly increasing in other application also such as sports, marine, electrical and electronics parts, furnitures, house wares etc. [14-16].

The dynamic mechanical analysis (DMA) has been widely used technique to characterize the thermal properties of NFRPCs. In DMA, a sinusoidal stress is applied on composite specimen and output strain is measured under the influence of frequency and temperature. Thermal properties such as storage modulus, loss modulus, damping, effectiveness constant of reinforcement and glass transition temperature of these composites can be easily and accurately obtained by DMA [17]. The glass transition temperature is an important output parameter of DMA, defined as a point where materials changes from glassy to rubbery state, can be obtained from either peak of loss modulus or Tan $\delta$ curve [18]. Many researchers had already reported studies on dynamic mechanical properties of NFRPCs, and highlighted that these composites have acceptable dynamic mechanical properties for many industrial applications [17-26].

Pothan et al. [27] carried out the dynamic mechanical analysis of banana fibre reinforced polyester composites and highlighted that the composite with $40 \mathrm{vol} \%$ fibres loading showed the maximum value of storage modulus and lower value of loss modulus and damping parameters. The dynamic mechanical properties of short sisal fibres reinforced polystyrene composites were studied and observed that the storage modulus decreased upon increasing the temperature and the glass transition temperature of composite shifted towards lower temperature as compared to neat polystyrene [28]. Mohanthy et al. [29] investigated an experimental study on the viscoelastic behavior of jute fibre reinforced high density polyethylene composites and observed 
that the storage modulus was found to increase with increase in fibres loading up to $30 \%$, and dynamic mechanical properties of oil palm fibre linear low density polyethylene bio composite in terms of storage modulus, loss modulus and damping parameter was investigated by Shinoj et al. [30]. They highlighted that the storage and loss modulus increased with increase in fibre content whereas the values of $\operatorname{Tan} \delta$ peak decreased. Dynamic mechanical properties of epoxy based composites reinforced by ramie fibres was carried out by Margem et al. [31]; reported that stiffness of epoxy increased due to incorporation of ramie fibres. Kumar et al. [32] carried out the mechanical, thermal and dynamic mechanical properties of coconut fiber reinforced epoxy composites. Dynamic mechanical properties in terms of storage modulus, loss modulus and damping of epoxy based composites reinforced with jute fibres [18], and sisal fibres [17] were reported.

Dynamic mechanical properties of polymeric materials not only depends upon temperature and frequency but also on used polymeric matrices, strength and stiffness of fibres, fibres loading, fibres length, fibres orientations and adhesion between fibres and matrix. Limited numbers of research papers are available on dynamic mechanical analysis of NFRPCs in which effect of variation of frequencies was studied. This gap motivated us to investigate the dynamic mechanical properties of jute composite at different frequencies.

\section{Experimental details}

\subsection{Materials}

Jute fibres were used as reinforcement and epoxy AY 105 with corresponding hardener HY951 as a matrix in this work. Jute fibre and epoxy matrix were purchased from local the resource. Epoxy resin has density 1.11 $\mathrm{g} / \mathrm{cm}^{3}$ and dynamic viscosity (at $25^{\circ} \mathrm{C}$ ) 11.79 Pa.s. The physical and mechanical properties, and chemical composition of jute fibre is provided in Table 1 [33].

Table 1: Physical, mechanical and chemical composition of jute fibre

\begin{tabular}{|r|r|}
\hline Properties & Jute fibre \\
\hline Density $\left(\mathrm{g} / \mathrm{m}^{3}\right)$ & 1.3 \\
\hline Diameter $(\mu \mathrm{m})$ & $25-200$ \\
\hline Elongation at break $(\%)$ & $1.5-1.8$ \\
\hline Tensile strength $(\mathrm{MPa})$ & $393-773$ \\
\hline Young's modulus $(\mathrm{GPa})$ & 26.5 \\
\hline Cellulose $(\%)$ & $61-71$ \\
\hline Lignin $(\%)$ & $12-13$ \\
\hline Microfibrillar angle & 8 \\
\hline Wax $(\%)$ & 0.5 \\
\hline Hemi- cellulose $(\%)$ & $14-20$ \\
\hline
\end{tabular}

\subsection{Fabrication of composites}

The composites were fabricated by reinforcing uni-directional jute fibres into epoxy matrix using hand-lay-up technique followed static compressive loading. Before starting the fabrication, the matrix material as a binder was prepared by mixing of epoxy and hardener in a ratio of 10:1 as recommended by the reputed suppliers. During fabrication process, a stainless steel mould having dimensions of $300 \times 200 \times 3 \mathrm{~mm}^{3}$ was used to maintain the dimensions of composite's laminates. The cast of each composite was cured under a load of $50 \mathrm{~kg}$ for $24 \mathrm{hrs}$ before it was removed from the mould. A releasing agent was used to assist easy removal of the cast composite's laminates from the mould after curing. The specimens were cut as per ASTM standard using a diamond cutter for the analysis of its dynamic mechanical properties. The composites manufactured with varying wt. \% of fibres are designated as shown in Table 2.

\subsection{Dynamic mechanical analysis}

The dynamic mechanical properties of jute fibre reinforced epoxy composites were studied using the dynamic mechanical analyzer (model, Seiko instruments DMA 6100). The dynamic mechanical properties were determined using three point bending mode as a function of temperature. The composites were cut into samples with dimensions of $50 \mathrm{~mm} \times 13 \mathrm{~mm} \times 3 \mathrm{~mm}$ as per ASTM D 5023. Experiments were carried out in the temperature range of $25-200{ }^{\circ} \mathrm{C}$ at different frequency as $1,2,5$ and $10 \mathrm{~Hz}$. The dynamic mechanical properties such as storage modulus, loss modulus, damping and glass transition temperature of prepared jute composites were investigated. 
Table 2: Nomenclature of jute composites

\begin{tabular}{|r|r|r|r|}
\hline Symbols & Composites & Symbols & Composites \\
\hline J10 & $\begin{array}{r}\text { Epoxy composite reinforced by 10 } \\
\text { wt.\% of jute fibres }\end{array}$ & J30F1 & $\begin{array}{r}\text { Epoxy composite reinforced by 30 wt.\% of } \\
\text { jute fibres at 1 Hz frequency }\end{array}$ \\
\hline J20 & $\begin{array}{r}\text { Epoxy composite reinforced by 20 } \\
\text { wt.\% of jute fibres }\end{array}$ & J30F2 & $\begin{array}{r}\text { Epoxy composite reinforced by 30 wt.\% of } \\
\text { jute fibres at 2 Hz frequency }\end{array}$ \\
\hline J30 & $\begin{array}{r}\text { Epoxy composite reinforced by 30 } \\
\text { wt.\% of jute fibres }\end{array}$ & J30F5 & $\begin{array}{r}\text { Epoxy composite reinforced by 30 wt.\% of } \\
\text { jute fibres at 5 Hz frequency }\end{array}$ \\
\hline J40 & $\begin{array}{r}\text { Epoxy composite reinforced by 40 } \\
\text { wt.\% of jute fibres }\end{array}$ & J30F10 & $\begin{array}{r}\text { Epoxy composite reinforced by 30 wt.\% of } \\
\text { jute fibres at 10 Hz frequency }\end{array}$ \\
\hline
\end{tabular}

\section{Results and Discussion}

\subsection{Dynamic mechanical properties at $1 \mathrm{~Hz}$ frequency}

Dynamic mechanical properties of prepared jute composites were studied in terms of storage modulus, loss modulus and damping. Descriptions are provided in following paragraphs.

\subsubsection{Storage modulus}

Storage modulus of polymer based materials imparts that how materials are stiffer. Fig. 1 shows the variation in storage modulus of jute composites as a function of temperature at $1 \mathrm{~Hz}$ frequency. Storage moduli of jute composites were found to increase with increase in weight percentages of jute fibres up to $30 \%$ then decreased due to improper adhesion between fibres and matrix [37]. In the glassy region, the highest value of $E^{\prime}$ was shown by composite J30 whereas its lowest value was shown by composite J10. Similar types of results as highest storage modulus at $30 \mathrm{wt}$ \% had been previously reported [13, 23, 37]. The highest value of $E^{\prime}$ for composite $\mathrm{J} 30$ could be due to strong interfacial adhesion between fibres and matrix. In all cases, the storage moduli were found to decrease with increase in temperature due to loss in stiffness of fibres at high temperature [24-26]. In transition region, all jute composites had a gradual fall in values of $E^{\prime}$ with increase in temperature. It could be credited to increase in molecular mobility after softening of polymeric composites with increase in temperature [24, 34]. In rubbery region, it was observed that the composite $\mathbf{J} 30$ had the highest value of $E^{\prime}$. The value of $E^{\prime}$ is directly proportional to the adhesion between fibres and matrix [35]. This fact show that jute composite J30 showed better interface bonding as compare to other jute composites. On the other hand, composite $\mathbf{J} 20$ had its lowest value due to increase in molecular mobility at higher temperature [25]. Moreover, it could be also observed that in rubbery region the storage moduli of jute composites were found close to each other. This is because at high temperature the fibres don't contribute much to impart to materials [30].

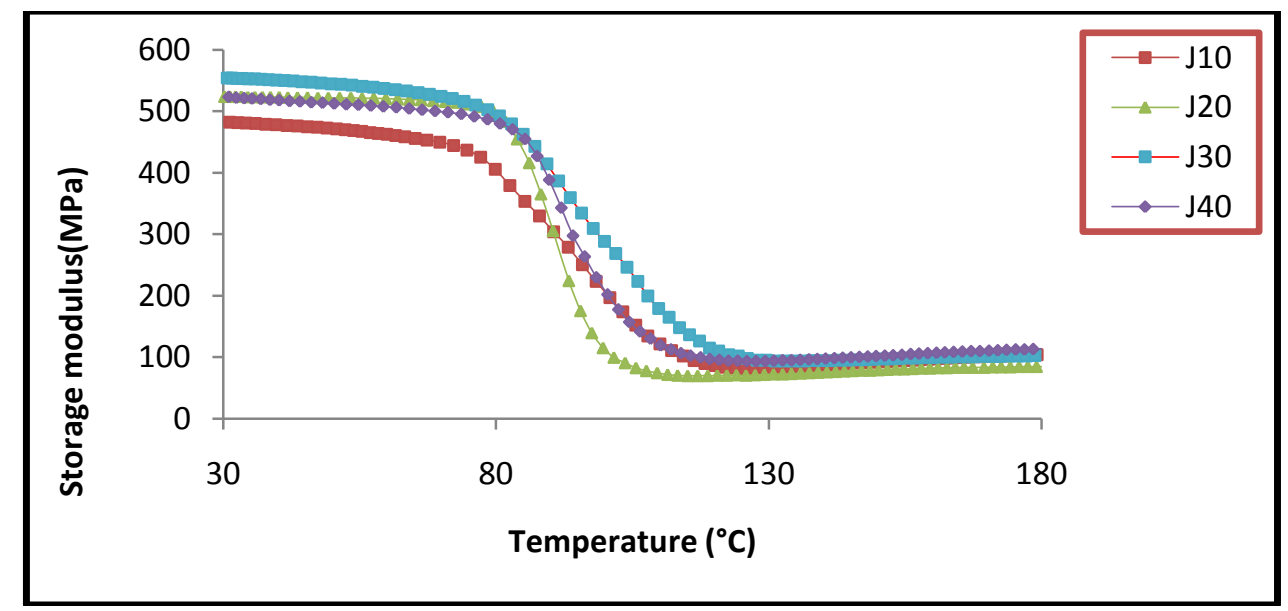

Figure 1: Variation in storage modulus with temperature of jute composites at $1 \mathrm{~Hz}$.

\subsubsection{Loss modulus}

Loss modulus is defined as maximum energy released by composite materials during deformation. It presents the viscous response of the materials which depends upon motion of polymeric molecules in the composites [23$24,34]$. The variation in loss modulus of jute composites as a function of temperature at $1 \mathrm{~Hz}$ frequency is shown in Fig. 2. In loss modulus curve, its peak presents the values of $T_{g}$ of corresponding composites. It could be seen that the values of $E^{\prime \prime}$ increased up to $T_{g}$ and then decreased with increase in temperature. The highest 
peak of $E^{\prime \prime}$ curve was shown by $\mathrm{J} 20$ followed by $\mathrm{J} 30$ as shown in Table 3 . The values of $T_{g}$ for the jute composites which is obtained from loss modulus curve is given in Table 3. The composite J30 showed the highest value of $T_{g}\left(100^{\circ} \mathrm{C}\right)$ which shows its better thermal stability than all other jute composites [26]. The higher thermal stability could be associated with the decrease in mobility of matrix due to incorporation of jute fibres [28].

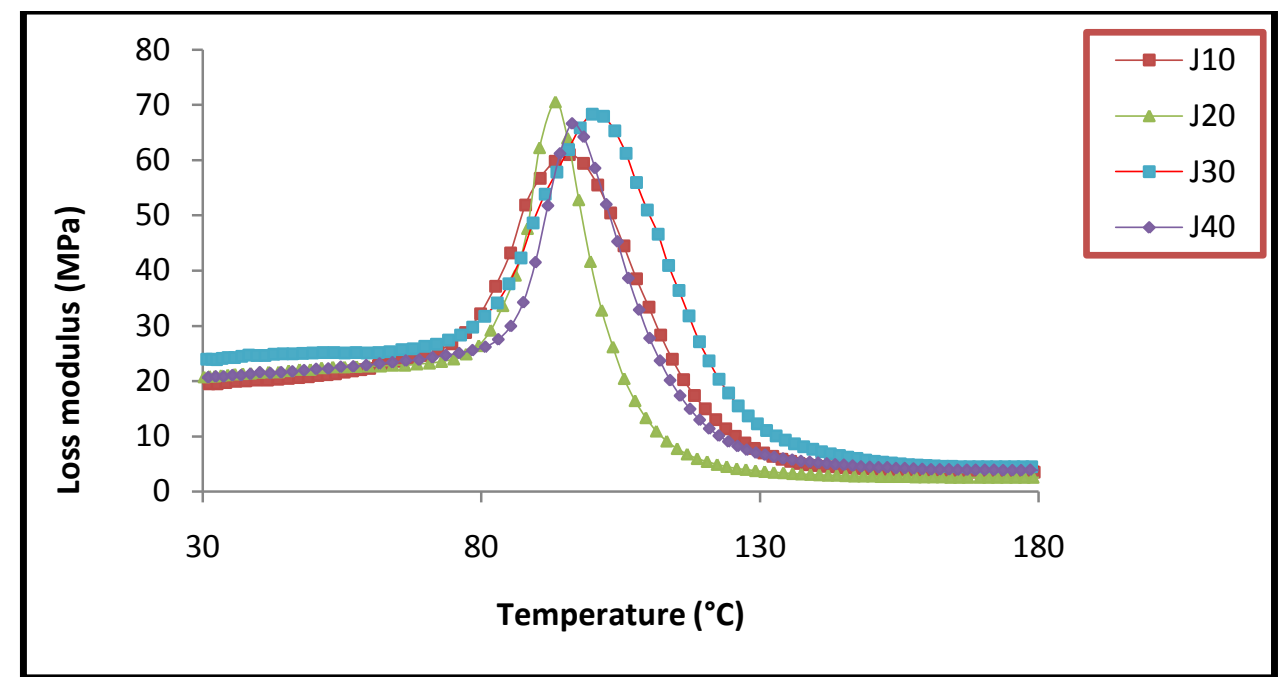

Figure 2: Variation in loss modulus with temperature of jute composites at $1 \mathrm{~Hz}$.

\subsubsection{Damping}

Tan delta or damping is the ratio of loss modulus and storage modulus which is related to impact resistance of the materials. Damping depends upon adhesion between fibres and matrix. Poor fibre-matrix adhesion associated with higher damping and vice-versa [36]. This fact can be explained as strong fibre-matrix adhesion could reduce the mobility of polymer chain turn into reducing damping [23]. Lower value of damping shows the good load bearing capacity of the composite [23]. At $1 \mathrm{~Hz}$ frequency, the variation in damping of jute composites as a function of temperature is shown in the Fig. 3.

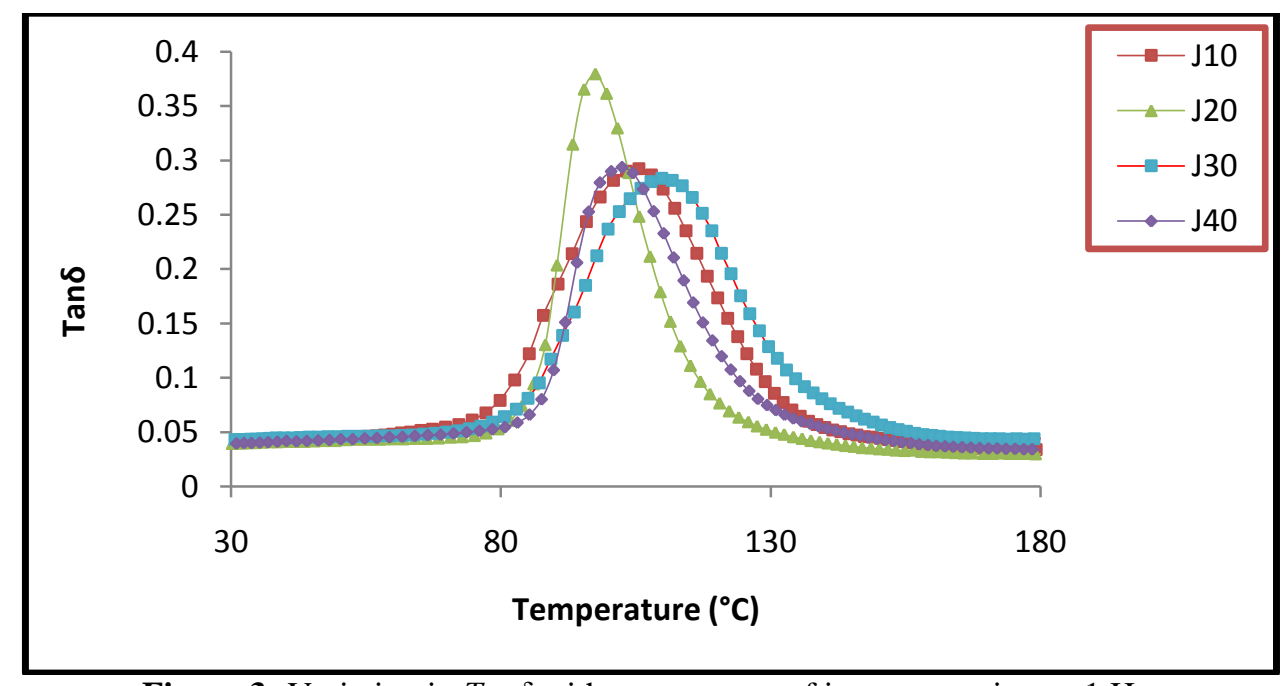

Figure 3: Variation in Tan $\delta$ with temperature of jute composites at $1 \mathrm{~Hz}$.

The highest peak of Tan $\delta$ curve was shown by J20; shows the better damping than all other jute composites. On the other hand, composite J30 showed the lowest peak of Tan $\delta$ curve; shows better load bearing capacity. This fact may be due to strong fibre-matrix adhesion leads to effective stress transfer. The shifting of $T_{g}$ towards higher temperature was found for jute composite J30. This is due to decreased mobility of polymer chain by addition of high strength jute fibres. The jute composite $\mathrm{J} 30$ had higher value of $T_{g}\left(110{ }^{\circ} \mathrm{C}\right)$ which shows its better thermal stability. The values of $T_{g}$ obtained from $\operatorname{Tan} \delta$ curve for jute composites is given in Table 3 . 
Table 3: Dynamic mechanical properties of jute composites at $1 \mathrm{~Hz}$ frequency

\begin{tabular}{|c|c|c|c|c|}
\hline Composites & $\begin{array}{c}\text { Peak height of } \\
\text { Tan } \delta \text { curve }\end{array}$ & $\begin{array}{c}T_{g} \text { from } \operatorname{Tan} \delta \\
\text { curve }\end{array}$ & $\begin{array}{c}\text { Peak height of } \\
\text { curve (MPa) }\end{array}$ & $E_{g}$ from $E^{\prime \prime}$ curve \\
\hline J10 & 0.292 & 106 & 61.0 & 96 \\
\hline J20 & 0.379 & 98 & 70.5 & 93 \\
\hline J30 & 0.284 & 110 & 68.3 & 100 \\
\hline J40 & 0.294 & 102 & 66.6 & 96 \\
\hline
\end{tabular}

\subsection{Dynamic mechanical properties at different frequencies}

After obtaining the better dynamic mechanical properties for jute composite J30, effect of increase in frequencies on its dynamic mechanical properties was studied as follows.

\subsubsection{Storage modulus at different frequencies}

The variation in storage moduli with temperature of jute composites at different frequencies is shown in Fig. 4. A considerable effect can be observed on storage moduli of jute composites because of variation in frequencies. In the glassy region, highest value of storage modulus was shown by jute composites at $2 \mathrm{~Hz}$ frequency and its lowest value was shown at $5 \mathrm{~Hz}$ frequency. In this region, increase in values of storage moduli due to increase in frequencies follows the order: J30F2 $>$ J30F10 $>$ J30F1 $>$ J30F5.

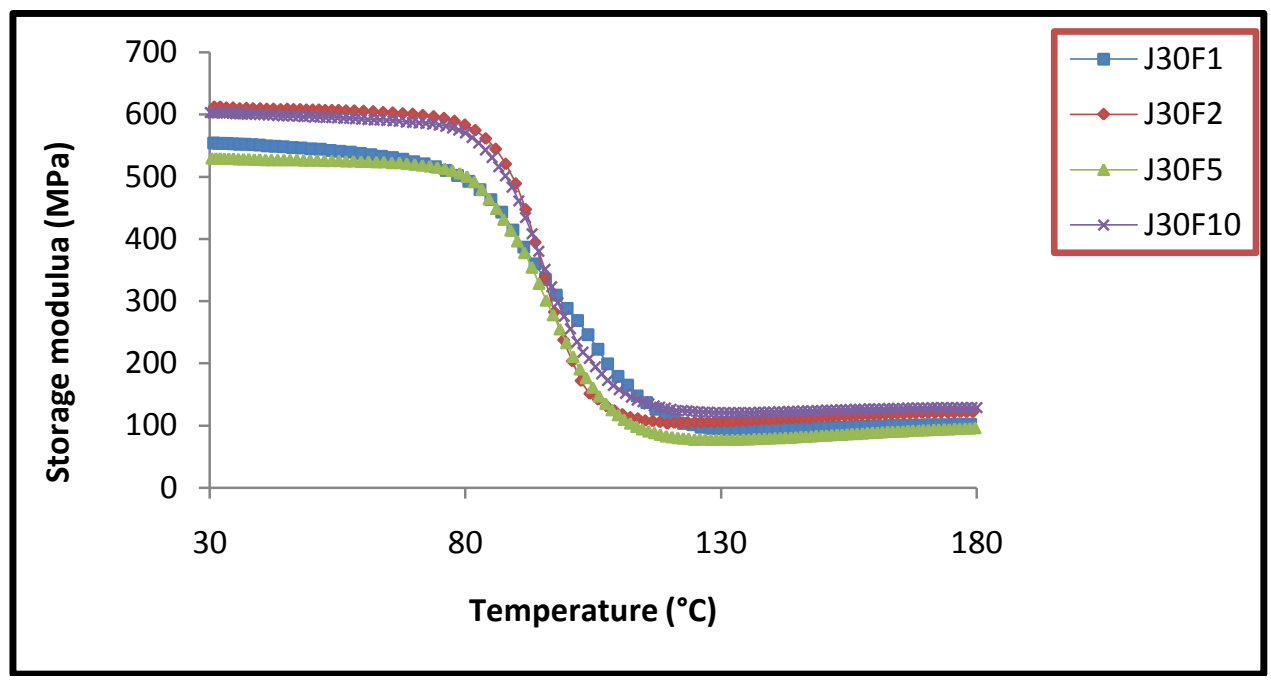

Figure 4: Variation in storage modulus with temperature of jute composites at different frequencies

In rubbery region, highest value of storage modulus was shown at $10 \mathrm{~Hz}$ frequency. A similar type of result as increase in storage moduli with increase in frequencies had been already reported in past literatures [38, 40]. This fact could be explained as stress was applied for a short time because of increase in frequencies leads to an effective transfer of stress [38]. However, its lowest value was shown at $5 \mathrm{~Hz}$ frequency, may be due to improper stress transfer. In this region, increase in values of storage moduli due to increase in frequencies follows the order: J30F10 $>\mathrm{J} 30 \mathrm{~F} 2>\mathrm{J} 30 \mathrm{~F} 1>\mathrm{J} 30 \mathrm{~F} 5$. It was also very interesting to observe that effect of frequencies at lower temperature (glassy region) was higher than at higher temperature (rubbery region).

\subsubsection{Loss modulus at different frequencies}

The variation in loss modulus of jute composites as a function of temperature at different frequencies is shown in Fig. 5. Similar to storage modulus results, a significant effect of variation in frequencies was also observed on loss moduli of jute composites. It could be observed that peaks of loss modulus curve were found to increase with increase in frequencies. The highest peak of loss modulus curve was shown for composite $\mathrm{J} 30 \mathrm{~F} 10$ followed by $\mathrm{J} 30 \mathrm{~F} 2, \mathrm{~J} 30 \mathrm{~F} 5$ and $\mathrm{J} 30 \mathrm{~F} 1$. The increase in highest values of loss modulus curve could be due to increase in molecular mobility with increase in frequencies [38]. It was interesting to notice that on increasing the frequencies the values of glass transition temperatures were found to reduce as shown in Table 4. This could be because of increase in frequency (increase in numbers of cycles per second), leads to losing of bonds between fibres and matrix. The highest value of glass transition temperature for jute composites at different frequencies follows the order: J30F1 $>$ J30F2 $>$ J30F5 $>$ J30F10. Thermal stability/glass transition temperature mainly depends upon adhesion between fibres and matrix which restricts the movement of polymers chain [39]. On increasing the frequencies, movement of polymers chain was increased and hence decreases in thermal stability. 


\subsubsection{Damping at different frequencies}

At different frequencies, the variation in $\operatorname{Tan} \delta$ of jute composites as a function of temperature is shown in the Fig. 6. The highest peak of damping was found to increase with increase in frequencies, as shown in Table 4. Thermal stability was also found to reduce with increase in frequencies. The highest thermal stability was found at lower frequency $1 \mathrm{~Hz}$, whereas lowest thermal stability was obtained at higher frequency $10 \mathrm{~Hz}$, as shown in Table 4. These results showed a considerable effect of variation in frequencies on damping of jute composites.

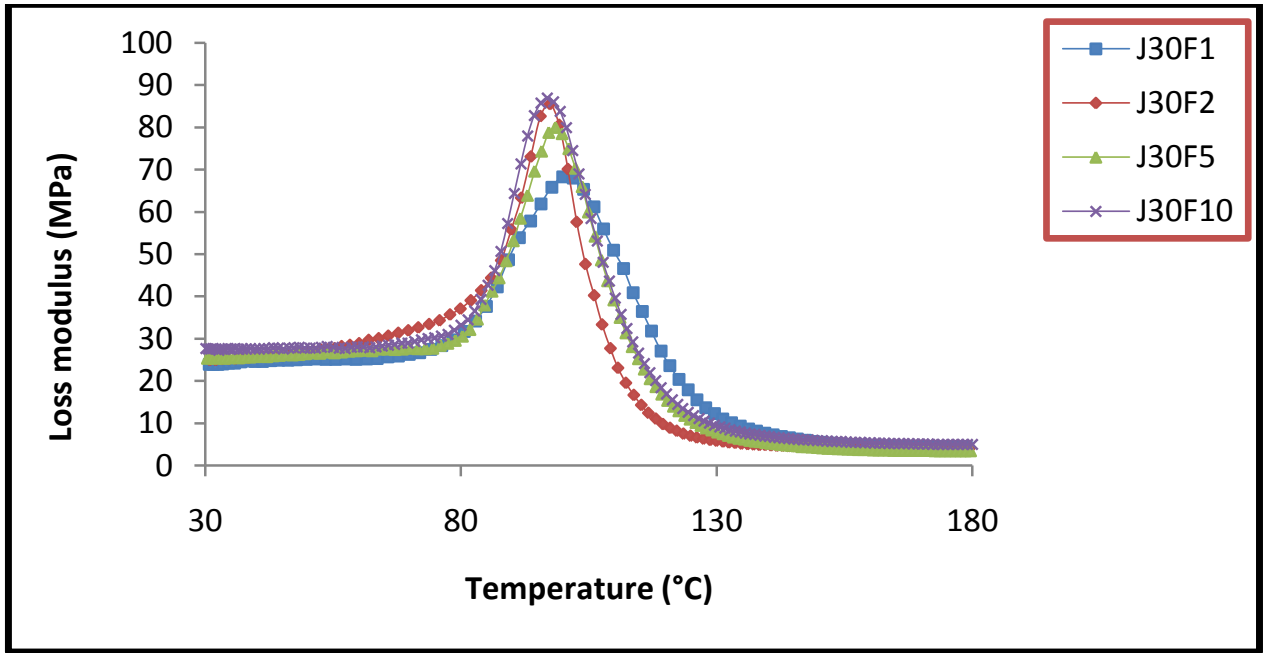

Figure 5: Variation in loss modulus of jute composites with temperature at different frequencies

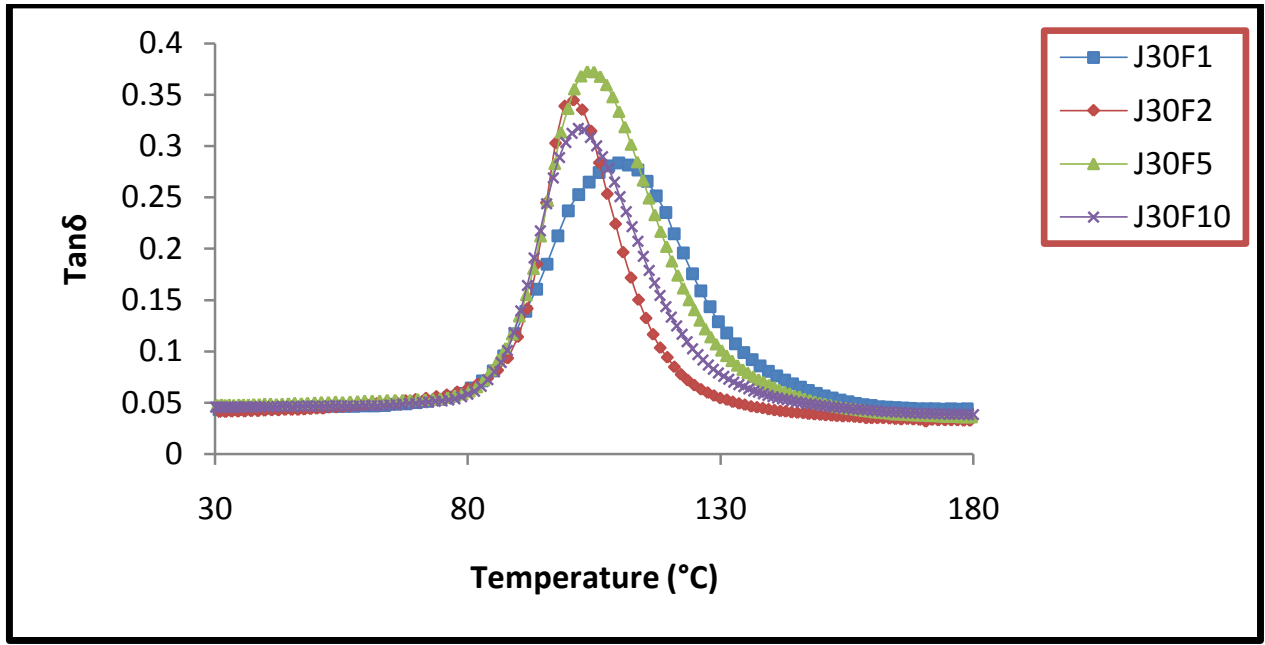

Figure 6: Variation in Tan $\delta$ with temperature of jute composites at different frequencies

Table 4: Dynamic mechanical properties of jute composites at different frequencies

\begin{tabular}{|r|r|r|rr|r|}
\hline Composites & $\begin{array}{c}\text { Peak height of } \\
\text { Tan } \delta \text { curve }\end{array}$ & $\begin{array}{c}T_{g} \text { from Tan } \delta \\
\text { curve }\end{array}$ & $\begin{array}{c}\text { Peak height of } E^{\prime \prime} \\
\text { curve (MPa) }\end{array}$ & $T_{g}$ from $E^{\prime \prime}$ curve \\
\hline J30F1 & 0.284 & 110 & 68.3 & 100 \\
\hline J30F2 & 0.344 & 101 & 85.4 & 97 \\
\hline J30F5 & 0.372 & 104 & 79.9 & 98 \\
\hline J30F10 & 0.317 & 102 & 87.0 & 97 \\
\hline
\end{tabular}

\section{Conclusions}

Dynamic mechanical properties of jute fibres reinforced epoxy composites were successfully investigated at different frequencies and following conclusions are obtained.

- Glass transition temperature and load bearing capacity were found maximum for jute composite having 30 wt. \% fibres content.

- On increasing the frequencies, storage modulus was found to increase and hence higher value of storage modulus was found at higher frequency in rubbery region. 
- The highest peak of damping was found at $1 \mathrm{~Hz}$ frequency but on increasing the frequencies it was found to reduce.

- Glass transition temperature/thermal stability was also found to reduce with increase in frequencies.

Acknowledgments- The authors would like to thanks the Head of Mechanical Engineering Department of Motilal Nehru National Institute of Technology Allahabad for their support in allowing us to perform the tests. The study is partially supported by Cumulative Professional Development Allowance (CPDA) Fund for teachers from Motilal Nehru National Institute of Technology Allahabad.

\section{References}

1. A. Gowthami, K. Ramanaiah, A.V.R. Prasad, K.H.C. Reddy, K.M. Rao, G.S. Babu, J. Mater. Environ. Sci. 4(2013) 199.

2. Hariom. Mourya, M.K.Gupta, R.K. Srivastava, H. Singh, Mater. Today: Proceed. 2 (2015) 1347.

3. Himanshu. Bisaria, M.K. Gupta, P. Sandilya, R.K. Srivastava, Mater. Today: Proceed. 2 (2015) 1193.

4. M.K.Gupta, R.K. Srivastava, Procedia. Mater. Sci. 5 (2014) 2434.

5. Avinash. Kumar, Manoj. Kumar.Gupta, R.K. Srivastava, Harinder. Singh, Int. J. Eng. Res. Manage. Technol. 1(2014)44.

6. Tanveer. Alam, M.K.Gupta, R.K. Srivastava, Harinder. Singh, Ajaya. Bharti, Int. J. Eng. Res. Manage. Technol. 1(2014)77.

7. M.A. Fuqua, S. Huo, C.A. Ulven, Polym. Rev. 52 (2012) 259.

8. M.K.Gupta, R.K. Srivastava, Himanshu. Bisaria, I. J. Fib. Text. Res. 5 (2015) 30.

9. B. Asaithambi, G. Ganesan, S. Ananda. Kumar, Fib. Polym. 15 (2014) 847.

10. K.S. Ahmed, S. Vijayarangan, J. Mater. Process. Technol. 207 (2008) 330.

11. M.K.Gupta, R.K. Srivastava, American. J. Polym. Sci. Eng. 4 (2016) 1.

12. P.K. Bajpai, I. Singh, J. Madaan, Wear. 297 (2013) 829.

13. M.K.Gupta, R.K. Srivastava, Indian. J. Eng. Mater. Sci. 23 (2016) 231.

14. M.K.Gupta, R.K. Srivastava, Polym. Plast. Technol. Eng. 55 (2016) 626.

15. K.L. Pickering, M.G.A. Efendy, T.M. Le, Compos: Part A. 83 (2016) 98.

16. M-P. Ho, H. Wang, J.H. Lee, C.K. Ho, K.T. Lau, J. Leng, D. Hui, Compos: Part B. 43 (2012) 3549.

17. M.K.Gupta, R.K. Srivastava, Indian. J. Fib. Text. Res. 41 (2016) 235.

18. M.K.Gupta, R.K. Srivastava, Indian. J. Fib. Text. Res. 42 (2017) 64.

19. M.K.Gupta, R.K. Gond, American. J. Polym. Sci. Eng. 5 (2017) 24.

20. M.K.Gupta, Vipul. Deep, American. J. Polym. Sci. Eng. 5 (2017) 53.

21. M.K.Gupta, R.K. Srivastava, American. J. Polym. Sci. Eng. 3 (2015) 198.

22. M. Idicula, S.K. Malhotra, K. Josheph, S. Thomas, Compos. Sci. Technol. 65 (2005) 1077.

23. D. Shanmugam, M. Thiruchitrambalam, Mater. Des. 97 (2013) 533.

24. M. Jawaid, H.P.S.A. Khalil, A. Hassan, R. Dungani, A. Hadiyani, Compos: Part B. 45 (2013) 619.

25. M.K.Gupta, R.K. Srivastava, Indian. J. Eng. Mater. Sci. 23 (2016) 37.

26. M.K.Gupta, J. Mater: Des. Appl. Part-L, 2016, DOI: 10.1177/1464420716646398.

27. L.A. Pothan, Oommen. Compos. Sci. Technol. 63 (2003) 283.

28. K.C.M. Nair, S. Thomas, G. Groeninckx, Compos. Sci. Technol. 61 (2001) 2519.

29. S. Mohanty, S.K. Verma, S.K. Nayak, Compos. Sci. Technol. 66 (2006) 538.

30. S. Shinoj, R.S. Visvanathan, S. Panigrahi, N. Varadharaju, Biosys. Eng. 109 (2011) 99.

31. F.M. Margem, S.N. Monteiro, J.B. NetoI, R.J.S. Rodriguez, B.G. Soares, Revista. Matéria, 15 (2010) 164.

32. S.M.S. Kumar, D. Duraibabu, K. Subramanian, Mater. Des. 59 (2014) 63.

33. O. Faruka, A.K. Bledzki, H.P. Fink, M. Sain, Prog. Polym. Sci. 37 (2012) 1552.

34. N. Hameed, P.A. Sreekumar, B. Francis, W. Yang, S. Thomas, Compos: Part A: Appl. Sci. Manuf. 38 (2007) 2422.

35. S. Keusch, R. Haessler, Compos. Part A: Appl. Sci. Manuf. 30 (1999) 997.

36. A.L.M. Hernandez, V. Santos, M. De Icaza, M.C. Victor, Compos: Part B, 38 (2007) 405.

37. S.K. Samal, S. Mohanty, S.K. Nayak, Polym. Plast. Technol. Eng. 48 (2009) 397.

38. M.H. Liu, R. Li, G. Wang, Z.Y. Hou, B. Huang, J. Therm. Anal. Calorim. 126 (2016) 1281.

39. N. Saba, M. Jawaid, O.Y. Alothman, M.T. Paridah, Const. Build. Mater. 106 (2016) 149.

40. S.S. Rana, M.K. Gupta, R.K. Srivastava, Mater. Today: Proceed. 4 (2017) 3387.

\section{(2018) ; http://www.jmaterenvironsci.com}

